Keywords: Pulmonaria Officinalis, Herbal remedies, Atropine intoxication, Delirium.

\title{
Acute atropine intoxication with psychiatric symptoms by herbal infusion of Pulmonaria officinalis (Lungwort)
}

\author{
Enrique Baca-García, M.D.* \\ Hilario Blasco-Fontecilla, M.D.** \\ Carlos Blanco, M.D.** \\ Carmen Díaz-Sastre, M.D.*** \\ María Mercedes Pérez-Rodríguez, M.D. ${ }^{* * *}$ \\ Jerónimo Sáiz-Ruiz, M.D., Ph.D. ${ }^{* \star *, * \star * \star *}$ \\ * Psychiatry Department. Fundación \\ Jiménez-Díaz Hospital, Madrid, Spain \\ ** Doctor R. Lafora Hospital, Madrid, Spain \\ *** Columbia College of Physicians and \\ Surgeons. Presbyterian Hospital, New York, \\ USA \\ **** Psychiatry Department. Ramón y Cajal \\ Hospital, Madrid, Spain \\ ***** University of Alcala, Madrid, Spain \\ SPAIN, USA
}

\begin{abstract}
Background and objectives: Lungwort infusion is a preparation extracted from Pulmonaria officinalis which is occasionally used as a folk remedy for the common cold. The current report aims to describe acute atropine intoxications with delirium caused by Lungwort infusion in several members of the same family.

Methods: Description of three case reports. Search of literature through Medline.

Results: Three generations of a same family presented acute and moderately severe atropine intoxications after drinking an infusion prepared with Pulmonaria officinalis.

Conclusions: Despite the lack of scientific evidence for its clinical use, medicinal plants continue being widely used. In spite of severe adverse effects reported, the general thought is that herbal remedies are harmless. To our knowledge, this is the first report of acute atropine intoxications with psychiatric symptoms secondary to Pulmonaria officinalis in several members of a family. We suspect that the lungwort infusion may have been contaminated with some other substance with atropinic properties.
\end{abstract}




\section{Introduction}

It has been estimated that at least 3-4\% of the population in Western countries use herbal remedies for therapeutic purposes ${ }^{1}$. Spending on herbal products in the United Kingdom amounts to $£ 40$ million a year, mainly from self prescription ${ }^{2}$. Recently, Ang-Lee, Moss \& Yuan ${ }^{3}$ recommended patients should be asked routinely about use of herbal remedies prior to surgery, basing their recommendation in the observation that $70 \%$ of patients failed to disclose such use in their study. We suggest this recommendation to be extended to patients who attend Accident and Emergency facilities and we here present a series of case vignettes in which three members of the same family manifested both somatic and psychiatric symptoms consistent with atropine intoxication after consuming an herbal infusion made with Pulmonaria Officinalis.

\section{Case reports}

\section{Case 1: The grandfather}

The grandfather, aged 76, suffered from two similar attacks of 'anticholinergic symptoms' shortly after taking an infusion of Pulmonaria Officinalis to treat a cold. Each episode lasted approximately 24 hours. Symptoms included intense mouth dryness, mydriasis, dizziness, paresis of lower extremities and urinary retention. During the episodes the patient engaged in repetitive behaviors and experienced disorientation, visual hallucinations, dysarthria and impairments in immediate and recent memory. $\mathrm{He}$ was initially diagnosed with new onset vas- cular dementia due to his age and prior history of hypertension.

\section{Case 2: The daughter}

The daughter, aged 42, suffered from dry mouth, blurred vision and urinary retention two hours after drinking an infusion derived from Pulmonaria officinalis. These symptoms were followed by intense anxiety, palpitations and mydriasis. The episode was diagnosed as a non-specific anticholinergic reaction, and the source of the intoxication was not identified despite extensive history taking. A correct diagnosis was only possible when the clinical episodes both her father and daughter were suffering were reported and linked with hers.

\section{Case 3: The granddaughter}

The 14-year-old granddaughter began to experience atropine symptoms two hours after the first infusion of Pulmonaria Officinalis was taken for treating a common cold. She started complaining of blurred vision and dry mouth, followed by urinary retention. Over the next five hours, during which she took two more glasses of the infusion, she became disoriented and experienced psychomotor agitation and visual hallucinations. Physical examination revealed mild tachycardia, dryness of skin, and non-reactive mydriasis. No other abnormalities on physical exam or laboratory tests -including urine toxicology- were found. The fact that she went on drinking the infusion allowed us to find the source of intoxication and retrospectively diagnose the other cases. She was admitted to hospital and recovered quickly using supportive measures. The family members stated that they did not mention the infusion intake because they thought "a natural remedy could never do harm". 


\section{Discussion}

Atropine intoxication is potentially lethal. In the most severe cases differential diagnosis with acute psychosis must be made. The diagnosis is based on clinical symptoms resulting from the inhibition of muscarinic cholinergic neurotransmission. The signs and symptoms can be stated according to the atropine equivalent dose $^{4}$ (see Table I). The most common signs and symptoms are flushing, dryness of skin and mucous membranes, mydriasis with loss of accommodation, altered mental status and fever. Additional manifestations include sinus tachycardia, decreased bowel sounds, functional ileum, urinary retention, hypertension, tremulousness, myoclonic jerking. Recognized central atropinic effects include ataxia, disorientation, short-term memory loss, confusion, hallucinations (visual and auditory), psychosis, agitated delirium, seizures (rarely), coma, respiratory failure and cardiovascular collapse. Commonly prescribed medications and herbal remedies with anticholinergic properties are listed in Table II $^{5}$. In 1998, the Toxic Exposure Surveillance System (US) reported 1,025 anticholinergic plant exposures; $36 \%$ resulted in moderate-to-major toxicity but no deaths were reported ${ }^{5}$.

Table I

Signs and symptoms of anticholinergic poisoning according to the atropine equivalent dose ${ }^{4}$.

\begin{tabular}{|c|c|}
\hline Dose & Effects \\
\hline $0.5 \mathrm{mg}$ & Slight decrease of heart rate; certain mouth dryness; inhibition of sweating. \\
\hline $1.0 \mathrm{mg}$ & $\begin{array}{l}\text { Definite mouth dryness; thirst; increased heart rate, occasionally preceded by decreased } \\
\text { heart rate; mild pupillary dilation. }\end{array}$ \\
\hline $2.0 \mathrm{mg}$ & $\begin{array}{l}\text { Fast heart rate; palpitations; remarkable mouth dryness; dilated pupils; close vision somew- } \\
\text { hat blurry. }\end{array}$ \\
\hline $5.0 \mathrm{mg}$ & $\begin{array}{l}\text { All the symptoms mentioned above but in remarkable degree; difficulty speaking and swa- } \\
\text { llowing; restlessness and fatigue; cephalalgia; dry and hot skin; difficulty urinating; decreased } \\
\text { intestinal peristaltism. }\end{array}$ \\
\hline $10.0 \mathrm{mg}$ & $\begin{array}{l}\text { All the symptoms mentioned above but in even more remarkable degree; fast and weak } \\
\text { pulse; nearly obliterated iris; very blurry vision; reddened, hot, and dry skin; ataxia; restlessness } \\
\text { and excitation; hallucinations and delirium; coma. }\end{array}$ \\
\hline
\end{tabular}

Table II

Medications and plants with anticholinergic properties ${ }^{5}$.

- Anticholinergics: Atropine, Scopolamine, Benztropine, Trihexyphenidyl.

- Antihistamines: Chlorpheniramine, Cyproheptadine, Doxylamine, Hydroxyzine, Dimenhydrinate, Diphenhydramine, Doxylamine, Meclizine, Promethazine.

- Antipsychotics: Chlorpromazine, Clozapine, Mesoridazine, Olanzapine, Quetiapine, Thioridazine.

- Antispasmodics: Clidinium, Dicyclomine, Hyoscyamine, Oxybutynin, Propantheline.

- Cyclic antidepressants: Amitriptyline, Amoxapine, Clomipramine, Desipramine, Doxepin, Imipramine, Nortriptyline, Protriptyline.

- Mydriatics: Cyclopentolate, Homatropine, Tropicamide.

- Plants: Amanita muscaria, Amanita pantherina, Arctium lappa, Atropa belladonna, Cestrum nocturnum, Datura suaveolens, Datura stramonium, Hyoscyamus Níger, Lantana camara, Solanum carolinensis, Solanum dulcamara, Solanum pseudocapsicum, Slanum tuberosum. 
Lungwort infusion is a preparation extracted from Pulmonaria Officinalis which is sometimes used as a folk remedy for the common cold and other medical problems ${ }^{6,7}$. The lungworts are the genus Pulmonaria of flowering plants in the family Boraginaceae, native to Europe and western Asia. Lungworts are perennial herbs that form clumps or rosettes. They are covered in hairs of varied length and stiffness, and sometimes also bear glands. The underground parts consist of a slowly creeping rhizome with adventitious roots. Flowering stems are unbranched, rough, covered with bristly hairs, usually not exceeding 25-30 $\mathrm{cm}$, with a few exceptions (P. mollis, P. vallarsae). The silvery-white spots on the leaves were thought to resemble lungs. The color of the flower in bud is often pink, which then changes to violet or blue as the flower matures ${ }^{8}$.

To our knowledge, the current paper appears to be the first report of atropine intoxication secondary to Lungwort infusion. There are no reports in the literature suggesting that Pulmonaria officinalis itself has atropinic properties. We suspect that the lungwort infusion may have been contaminated with some other substance with atropinic properties. Similar cases of anticholinergic intoxications due to contamination of herbal infusions have been reported. For example, Hsu et al..$^{9}$ reported seven cases of anticholinergic poisoning from a herbal preparation (Paraguay tea) contaminated with belladonna alkaloids. What struck us most was to find out there were almost no scientific references regarding Pulmonaria Officinalis or Lungwort -only 10 references in Medline- while the information on nonscientific webs was overwhelming.

In recent times there has been an increase in the use of 'alternative remedies' ${ }^{2,3}$. There is a growing risk of intoxication due to their inner pharmacological properties, the potential presence of contaminating substances or interactions with other medications. This may result in novel clinical presentations, thus complicating the diagnosis of otherwise recognizable syndromes. In addition, most herbal remedies available in the developed countries are sold as food supplements ${ }^{10}$, thus evading thorough regulation of their quality and safety. Moreover, as in the cases reported, the general population may not consider them as either medication or as potentially toxic. Accidental or deliberate intoxication is one of the more frequent presentations to Accident and Emergency Departments. Up to $5 \%$ of patients presenting to an emergency department have taken an overdose, and the drugs taken most often include non-therapeutic substances like herbal products ${ }^{11}$. Unfortunately, many doctors have little knowledge of alternative medicine, and therefore diagnoses and treatment may be inappropriate. Increased attention in medical curricula, awareness of toxicity of natural medicines and systematic inclusion of questions about alternative treatments in the clinical history are necessary to minimize the risk of negative outcomes associated with the use of complementary or alternative reme$\operatorname{dies}^{2,10,11}$.

One limitation of the present report is the fact that the presence of belladonna alkaloids in urine samples was not investigated, as was done in other case reports 9,12 .

\section{References}

1. Eisenberg DM, Kessler RC, Foster C, Norlock FE, Calkins DR, Delbanco TL. Unconventional medicine in the United States. Prevalence, costs, and patterns of use. N Engl J Med 1993; 328 (4): 246-252.

2. Vickers A, Zollman C. ABC of complementary medicine. Herbal medicine. BMJ 1999; 319 (7216): 1050-1053. 
3. Ang-Lee MK, Moss J, Yuan CS. Herbal medicines and perioperative care. JAMA 2001; 286 (2): 208-216.

4. Brown JH, Taylor P. Agonistas y antagonistas de los receptores muscarínicos. In: Hardman JG, Limbird LE, Goodman, Gilman A, editors. Goodman \& Gilman's Las bases farmacológicas de la terapéutica, ed 10; New York: McGraw-Hill; 2003. pp. 162-181.

5 . Bruns JJ. Toxicity, Anticholinergic. eMedicine Journal 2001; 2 (6): 1-9.

6. Chevallier. A. The Encyclopedia of Medicinal Plants. London: Dorling Kindersley; 1996.

7. Ivanova D, Gerova D, Chervenkov T, Yankova T. Polyphenols and antioxidant capacity of Bulgarian medicinal plants. J Ethnopharmacol 2005; 96 (1-2): 145-150.

8. Wikipedia contributors. Lungwort. Wikipedia, The Free Encyclopedia; 2006. Available at: http://en.wikipedia. org/w/index.php?title=Lungwort\&oldid=91286877 [accessed 18 December 2006]
9. Hsu CK, Leo P, Shastry D, Meggs W, Weisman R, Hoffman RS. Anticholinergic poisoning associated with herbal tea. Arch Intern Med 1995; 155 (20): 2245-2248.

10. Ernst E. Herbal medicines: Where is the evidence? BMJ 2000; 321 (7258): 395-396.

11. Fatovich DM. Emergency medicine. BMJ 2002; 324 (7343): 958-962.

12. Nogue S, Pujol L, Sanz P, de la Torre R. Datura stramonium poisoning. Identification of tropane alkaloids in urine by gas chromatography-mass spectrometry. J Int Med Res 1995; 23 (2): 132-137.

Address for correspondence:

Dr. Enrique Baca García

Psychiatry Department. Hospital Fundación Jiménez-Díaz, Avda. Reyes Católicos, 2

28040 Madrid, Spain.

Telephone/fax: +34 915504987

e-mail: ebacgar2@yahoo.es 


\section{Linguistics \& Language Behavior Abstracts}

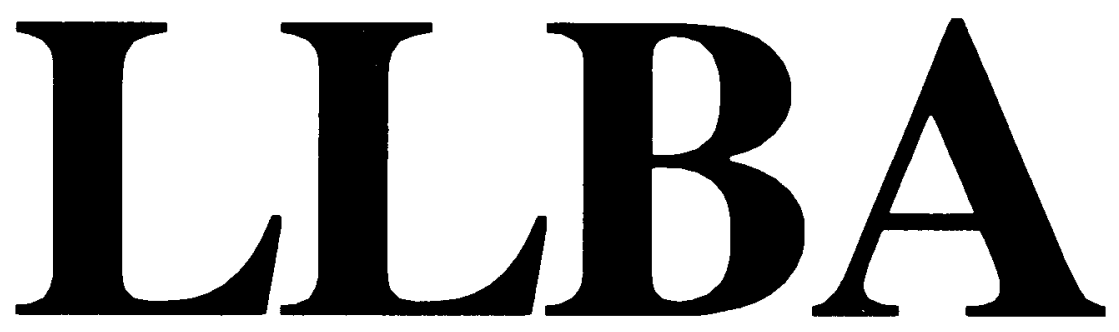

Now entering our 26 th year $(135,000$ abstracts to date) of senvice to linguists and language researchers worldwide. LLBA is available in print and also online from BRS and Dialog.

Linguistics \& Language Behavior Abstracts

P.O. Box 22206

San Diego, CA 92192-0206

Phone (619) 695-8803 FAX (619) 695-0416

Fast, economical document delivery available. 